\title{
User Challenges and Successes with Mobile Payment Services in North America
}

\author{
Serena Hillman, Carman Neustaedter, Erick Oduor and Carolyn Pang \\ School of Interactive Arts and Technology, Simon Fraser University \\ 250-13450 102 ${ }^{\text {nd }}$ Avenue, Surrey, British Columbia, Canada \\ shillman@sfu.ca, carman_neustaedter@sfu.ca, eoduor@sfu.ca, and carolyn_pang@sfu.ca
}

\begin{abstract}
Mobile payment services have recently emerged in North America where users pay for items using their smartphones. Yet we have little understanding of how people are making use of them and what successes and challenges they have experienced. As a result, we conducted a diary and interview study of user behaviors, motivations, and first impressions of mobile payment services in North America in order to understand how to best design for mobile payment experiences. Participants used a variety of services, including Google Wallet, Amazon Payments, LevelUp, Square and company apps geared towards payments (e.g., Starbucks). Our findings show that users experience challenges related to mental model development, pre-purchase anxiety and trust issues, despite enjoying the gamification, ease-of-use, and support for routine purchases with mobile payments. This suggests designing a better mobile payment experience through the incorporation of users' routines and behaviors, gamification and trust mechanism development.
\end{abstract}

\section{Author Keywords}

mobile payment services, Google Wallet, LevelUp, Square, PayPal, ubiquitous commerce, eCommerce, mCommerce, gamification

\section{ACM Classification Keywords \\ H.5.2 [User Interfaces]: User-Centered Design}

\section{INTRODUCTION}

It is now possible to pay for items in North America (United States and Canada) using smartphones via a variety of mobile payment services. This includes carrier billing (e.g., Text2Pay), near-field communications (e.g., Google Wallet), closed loop mobile payments (e.g., Starbucks app), and card readers (e.g., Square). With the recent addition of large online players (Google and Amazon), as well as more traditional payment entities (MasterCard and PayPal), and some well-developed startups (e.g., LevelUp and Square), expectations for a societal shift towards ubiquitous commerce-eCommerce activities occurring from virtually

Permission to make digital or hard copies of all or part of this work for personal or classroom use is granted without fee provided that copies are not made or distributed for profit or commercial advantage and that copies bear this notice and the full citation on the first page. Copyrights for components of this work owned by others than ACM must be honored. Abstracting with credit is permitted. To copy otherwise, or republish, to post on servers or to redistribute to lists, requires prior specific permission and/or a fee. Request permissions from Permissions@acm.org.

MobileHCI '14, September 23 - 26 2014, Toronto, ON, Canada Copyright 2014 ACM 978-1-4503-3004-6/14/09 \$15.00.

http://dx.doi.org/10.1145/2628363.2628389 any location-is both high and deemed of "critical importance" [16] for the future of mobile and electronic commerce.

While a number of studies have looked at mobile payment services in developing countries [7], and even developed countries in Europe [16,17] and Asia [11], this past body of work has not focused on the North American market and smartphones. These past studies were also focused on SMScentric mobile payments, rather than smartphone-based payment. Mobile payment services have just started to become available on smartphones in North America; therefore, collecting empirical data on their usage prior to the last couple of years was not possible.

Our research fills this gap with a study of existing and new mobile payment users in North America. We wanted to understand the experience from the perspective of those who had already adopted and integrated mobile payments into their purchasing routines, as well as those who were using it for the first time. The former allows us to understand those who have had relative success with mobile payments, while the latter allows us to understand first impressions and the people who may choose to not adopt the technology for longer term usage. We focused on uncovering the challenges and successes they faced. We also specifically explored trust concerns as they have been cited as a major barrier to the adoption of eCommerce [16].

Our findings showed that designing mobile payment services around routines and habits aids in a positive user experience. Users also appreciate gamification aspects associated with mobile payments and find that transactions create a socially cohesive experience, despite pre-purchase anxiety. Our results also revealed that mobile payments are not without their problems. Some users currently lack the mental model needed to see a clear benefit for mobile payments. Moreover, from a trust perspective, we saw that trust levels between vendor and user are notably worse for mobile payments than that reported for mCommerce activities and that trust mechanisms in this area need to be developed further. Together, this suggests design directions to increase the adoption of mobile payments by users while lessening usability and trust concerns.

\section{RELATED WORK}

There exists a variety of research on mCommerce, mobile payment services, and trust in eCommerce. We discuss research in these key areas to inform and situate our study. 


\section{mCommerce and Mobile Payment}

eCommerce has traditionally been viewed as a stationary act, performed at desktop computers in offices, homes, or other locations. Within this space lies mobile commerce (mCommerce): commerce activities occurring on a mobile device. Mobile payment services have been classified as a subset of mCommerce and a form of eCommerce [17]. The definition of mobile payment services has varied to include payment over any mobile communication device [21] to a more focused definition around just payments on mobile phones [6]. In our study, we adopt the later definition, similar to that of Schierz et al. [17]: "all payments for goods, services and bills authorized, initiated or realized" [17] using a mobile phone. Thus, mobile payments include paying for items in a store using a mobile device, as well as paying bills or transferring money using smartphone apps. The former takes place in a physical store like traditional commerce and the latter could take place in any location. While seemingly valuable, there have been noted shortcomings when comparing mobile payment growth in North America to its expectations [20]. Lack of adoption has been blamed on poor usability [20], social and cultural ideologies [12], and mobile technology limitations [10].

There have also been some studies that look specifically at mobile payments, yet none have focused on North American usage or smartphones. Instead, studies have focused on earlier versions of mobile payments (using SMS) in industrialized countries in Europe. First, Schierz et al. [17] analyzed mobile payment usage in Germany based on the Technology Adoption Model. This model explains that the adoption of technologies is based on the perceived usefulness and ease-of-use of the technology $[1,3]$. Findings show that perceived ease of use, compatibility, security, and usefulness, along with individual mobility positively affected users' attitudes towards mobile payments.

Second, and the closest study to our own in terms of its findings, Mallat [16] explored mobile payments in Finland in 2002 when they were based solely on SMS (direct billing). Results showed that users found mobile payments faster and more convenient than cash; mobile payments were most compatible with small value payments; and complexities around the use of the systems along with a lack of large merchant acceptance were barriers to adoption [16]. Users also described issues with trust where they had feelings of "vagueness" and "perceived lack of control." Users were also concerned about trust in network reliability and having their phone accessed if it was hacked, lost, or stolen [16]. While valuable, we caution that this study focused on feature-phones, not smartphones. Technology and culture have also dramatically changed since 2002 .

Mobile payment services have also been studied in nonindustrialized countries. In Kenya M-Pesa has seen tremendous success reporting 19 million subscribed users, which accounts for two-thirds of the entire adult population
[19]. China has also found some success with Alipay [18] and GCash has had well documented success in the Philippines [1]. Use for these systems is often fueled by users' lack of trust in their local country's banking systems along with a range of other social and cultural motivators [7,16,17]. Hinman and Matovu [7] investigated opportunities and challenges around mobile-based finances in rural Uganda. Their study found that users had a strong affinity to fixed assets, lacked access to capital, did not understand how mobile payments worked, and, overall, were confused by the mental model used to interact with the service [7]. Unlike developed nations, Ugandans lacked the reference point of transferring funds from person-to-person [7].

Together, the related research on mobile payment services shows a mixture of challenges and successes for the technology. Yet this past research does not explore mobile payments in North America using smartphone technology to understand how present day technology affects shopping behaviors and how to best design for such experiences. This is the focus of our study.

\section{eCommerce Trust}

In order to build trust in eCommerce environments, one usually relies on trust mechanisms such as third-party certifications and user-to-user relationships [5,10]. Even still, trust has historically been a major obstacle for the success of eCommerce $[15,16]$. The notion that users are vulnerable and likely to expose themselves during an online purchase is often a main concern [5]. Thus, past research has shown that the level of trust established in the uservendor relationship dictates if a transaction will occur and to what scope [15]. Past work has shown that not only does trust play a key role in the adoption of new technologies and the initial trust with a new vendor; it also results in repeat purchases and continued relationships [5].

Moving from traditional eCommerce on computers to mCommerce on mobile devices, we see that trust is less of a concern for users. Hillman et al. [8] studied shopping and purchasing on mobile phones (not mobile payment services) and found that mCommerce users had few trust concerns while making transactions on their mobile devices over the Internet. They found this was because trust was built through: direct brand awareness; the 'app' approval process; and, purchase recommendations by friends and family. Within this, brand played the most significant role in trust for mobile commerce activity.

Turning to mobile payments in North America, we do not see any study of the trust issues that users face or the ways in which such concerns might be mitigated. While part of mCommerce, mobile payments present a mixed-context. On one hand, they are different than mobile shopping activities because they can be performed in a retail store, the same as traditional shopping. Yet they can also be performed outside of a store from nearly any location as a form of bill payment or money transfer online. This mixed-context 
brings into question the legitimacy of eCommerce trust models for understanding mobile payment services as well as mCommerce trust models. Our study addresses this topic by exploring the trust issues that users face with mobile payments.

\section{STUDY METHODOLOGY}

The goal of our study was to understand how people use mobile payments in North America and what successes and challenges they faced. We explored this from the perspective of new and existing mobile payment users.

\section{Participants}

We recruited 21 participants (11 female) through postings on online forums and word of mouth. Ages ranged from 21 to 49 , with a median age of 27 . All participants lived in major metropolitan cities in North America (Canada and the United States). Occupations of participants varied heavily, e.g., engineer, graphic designer, social worker, student, web developer. Participants had average to expert technical abilities and all owned a smartphone. About half of the participants used an iPhone, while the other half used an Android device.

We purposely chose to investigate two groups of participants: existing users and new users. This allowed us to understand the experience from the perspective of those who have had relative success with mobile payments, leading to their repeated usage or long term adoption, as well as the first impressions of new users who may or may not choose to adopt the technology for longer term usage. Based on their own descriptions, we classified eleven users as existing users and ten participants as new users who had never tried a mobile payment service prior to the study. The amount of experience that existing users had in using mobile payments varied between two weeks and four years with a median of $\sim 6$ months. Existing users used mobile payments on average twice a week.

\section{Method}

Our study method varied depending on whether a participant was an existing or new user of mobile payment services.

\section{Method 1: Existing Users}

Existing users participated in a semi-structured interview that focused on their past and current experiences with mobile payment systems. Interview questions were based on understanding the participant's specific instances of use and why they used the services the way they did. Sample questions included: What mobile payment services have you used? When was the first time you used a mobile payment service and why? When was the last item you purchased using a mobile payment and why did you choose this payment method over another? What time of day was the purchase made and why? Interviews usually lasted between thirty and sixty minutes.

\section{Method 2: New Users}

After the data collection of Method 1 was complete, ten new users, who had not used mobile payments before were asked to complete an e-diary over a two-week period while trying out any mobile payment service(s) of their choosing. The diary method was chosen specifically to capture the user's experience in-the-moment over the first two weeks of use. This method has been used in similar studies $[8,9]$. During the two weeks, participants were asked to complete a minimum of four diary entries though we anticipated that some people may not complete this requirement if they simply found mobile payments too difficult to use or it did not meet their routines. A diary entry was required for every instance of purchasing that they attempted. The four diary entry minimum was chosen as four was the average number of completed transactions by existing users in Method 1 over a two week period.

The diary entry was a web form which had fields asking the participants for the following information: title of the activity, date, time and location of the purchase, if they had any trust concerns when completing this activity, why they used a mobile payment and not cash/credit/debit, a summary of the purchase, and their satisfaction level of the experience. Participants were told to complete the diaries as soon as possible after the purchase. This could be done on their phones in the moment, or later in the evening when at home. Participants opted to do a range of behaviors for recording entries.

After participants completed the diary entry phase, they participated in a semi-structured interview. During the interview, which also took between thirty and sixty minutes, participants were asked to review each of their diary entries and expand and/or clarify their entries. After, they were asked questions about the overall experience.

Existing users did not complete diary entries as we were interested in their summative experiences across their entire experience of using mobile payments, rather than a small portion of time, which would have been captured by diaries.

Participants used a variety of mobile payment options. These fell into one of four categories based on the types of mobile payment methods available in North America:

1. Closed Loop Mobile Payments (e.g., Starbucks App): the consumer uses an app on their smartphone to pay, typically by scanning a barcode at the register ( 7 new users, 7 existing users).

2. Carrier Billing (e.g., Text2Pay): the consumer pays by text message and the charge is added to their phone bill (1 new user, 2 existing users).

3. Card Readers (e.g., Square): these solutions allow merchants to take payment via a card reader attached to a smartphone or tablet ( 2 new users, 2 existing users).

4.Near-Field Communications (e.g., Google Wallet): the consumer can pay at the point of sale by waving their phone in front of a terminal ( 0 new users, 3 existing users). 
As can be seen, most users focused on closed loop payments given that they are currently more widely available in North America. The skew of new users to closed loop payments (e.g., Starbucks app) speaks to what participants were comfortable using mobile payments for and the monetary value and potential risk during the start of their usage. Because our participants used a variety of mobile payment services, our study reveals behaviors across a range of mobile payment options rather than findings specifically on any one payment solution. Despite this diversity, our results are fairly homogenous around all of the mobile payment services that participants used. We also feel this allowed us to explore the mobile payment research space as a whole, rather than a targeted study of just one type of payment option.

\section{Data Collection and Analysis}

We collected audio recordings of all interviews, notes from the interviews, and users' diary text. Interview recordings were later transcribed. All data was analyzed using open, axial, and selective coding. Each user group was first analyzed separately. We then reviewed the data from both groups together to compare and contrast experiences. Our coding revealed several main themes that relate to the success and challenges that our participants faced when using mobile payment services. We also found several ways in which existing and new users differed. We outline these differences along with our main themes in our results.

\section{PURCHASING ACTIVITIES}

Existing users reported purchasing a wide range of products and services using mobile payments. This included: coffee, clothes, sporting goods, electronics, furniture, extracurricular activities, and even school tuition. These products ranged in price from a $\$ 2$ cup of coffee to around $\$ 3,000$ for school tuition; however, the majority of items were between $\$ 2$ and $\$ 50$. Some participants also told us that they paid bills and made bank transfers to individuals using a mobile app. While this was not about purchasing items, it does fall in to the definition of mobile payment services [17].

During the two weeks, new users purchased coffee, and made bill payments and bank transfers to individuals. New users' product prices ranged from $\$ 2$ to $\sim \$ 150$. Although we asked participants to complete four diary entries over the two weeks, participants completed an average of 2.3 entries. Three new users did not complete any transactions even though they tried or thought about paying but did not understand; we followed up on these instances in our interviews. Without these three outliers, the average number of diary entries / purchases was 3.2. This illustrates that purchasing with mobile payments was an activity that typically occurred a couple of times a week for the new users. Thus, it was not a habitual or routine activity, which is to be expected for new usage when a person is still establishing a routine.
Within these purchase activities and experiences, our findings revealed clear successes that participants had in terms of mobile payments creating positive purchasing experiences. In addition, we also saw clear challenges that mobile payments posed for participants. Our results focus on these two main sections.

\section{USER SUCCESSES WITH MOBILE PAYMENT}

Participants had a variety of successes using mobile payments. These focused on routines, ease-of-use and usefulness, gamification, regulatory avoidance, and social perception. We describe each in turn.

\section{Habitual Routines}

First, we found that mobile payments were best for habitual purchases - purchases that were frequent and re-occurring. Participants who used mobile payments as a part of habitual purchasing activities felt they worked well and they liked them because they could easily fit in to their 'routine.' Half of the existing users very clearly had a daily habitual-type routine when using their payment service. Some understood this explicitly while others were only tacitly aware of the routine nature of their purchases. For example, when asked how often P6 (existing user) used mobile payments, she told us "everyday". She then described the time of day and variations based on her weekend and weekday schedule.

I rarely go to any other coffee shops [now]... I've just got accustomed to Starbucks... - P6, existing user

Other existing users had similar comments on how they liked mobile payments because they fit well into their routine:

I have my cell phone already in my hand because I listen to a podcast every morning, all it is pause the podcast, get coffee... Always the same time of day... 7:45 in the morning... on my way to work. - $\mathrm{P} 4$, existing user

Participants told us that using a mobile payment service made them more loyal to a particular store. For example, P4 told us that the mobile payment process was so "easy" that she frequented the store more often instead of going to a variety of stores. We caution that this did not mean that they increased the frequency in which they made purchases. Instead, it meant they opted for the same store each day as opposed to competitor stores. For example, if they purchased coffee once a day before using a mobile payment, they would continue to purchase coffee once a day. However, now they would avoid stores that did not offer the mobile payment solution.

Three new users also reported that they had a habitual routine for using mobile payments. For example, P12 also found it easy to integrate mobile payments into her daily routine and commented on how surprised she was that it was so easy to integrate:

I think how quickly I became accustomed to doing it. I just don't even think about it anymore, [it's] just how I pay for things now. $\mathrm{P} 12$, new user 
Five existing users and three new users had more of a semihabitual routine. While their purchases were not daily and at a particular time of day, these users reported that they made purchases at the same place in certain time intervals for re-occurring purchases. For example, this included utility bill payments, purchases of coffee a couple of times a week, or tuition payments for school that were paid once each term.

Moreover, participants suggested that the best services for mobile payments were heavily related to transactions that were frequent and routine, such as gas purchases, bill payments, and groceries. For example, P6, an existing user, told us that she wished she could use mobile payments for gasoline purchases, because she filled up her car every few days or so. P4, also an existing user, and P12, a new user, had similar thoughts around grocery store purchases as well:

I wish gas stations and grocery stores accepted mobile payment. $\mathrm{P} 4$, existing user

If my grocery store had it, that would be great. I would be reluctant to use an app like that in a place that I am not a regular patron. - P12, new user

Participants also expressed disappointment when they tried to find ways to use mobile payments to pay their recurring monthly bills. For example, P18, a new user, was unhappy that her power company did not have a mobile payment app:

Another thing that was really surprising for me was that there was no app for paying your hydro bill because... [this is] important for me. - P18, new user

\section{Ease-of-Use and Usefulness}

When asked about the benefits of using mobile payments, all participants mentioned ease-of-use, with no bias toward any particular type of mobile payment service. When asked to elaborate, responses mostly included two key elements: The process was easy and faster than other payment methods. For example, P17, a new user, described how the mobility and shortcut to make a bill payment allowed him to multi-task while in a university class:

It was nice to actually be able to take care of [paying my bills]... when it popped into my head I wasn't doing anything and I was able to [pay some bills], so I just pulled out my phone and did it. Which was kind of a new thing for me and I actually really liked that. It felt very productive too, to get something like that done; I felt like I accomplished something in class today. - P17, new user

Second, and somewhat surprisingly, mobile payments made it so payment methods were more often ready-at-hand and available when needed at a store. For example, a number of existing users mentioned that they often forgot their wallets but never their phones. In fact, these participants described paying by phone as a more natural process than using their wallet.

You always have your cell phone; I mean you forget your wallet nowadays way more than you do your cell phone. It is just easier to use. A lot of people have it in their pocket and it's just right there as opposed to ... trying to get your wallet and everything and so it just makes everything easier, one little device. - P4, existing user

It was just easier to have my phone out than take my wallet out and find a card. - P2, existing user

\section{Gamification and Entertainment}

Many mobile payment services that are designed as smartphone apps provide gamification elements where a user can score points, level-up, and receive rewards for purchases. The majority of users mentioned that they enjoyed the gamification of the mobile payment service they used. In fact, they would often describe the experience of purchasing as "more entertaining" and "funner" because of the gamification.

For example, P12, a new user, described how much she enjoyed seeing the stars from the Starbucks app "dropping in the cup," indicating she was getting closer to a free drink. This "elevated" the transactional experience compared to paying by credit card or cash. In this case, Starbucks has taken a desired action, buying Starbucks coffee, which is not normally game related and attached a game mechanism around collecting stars for rewards with every purchase. LevelUp also uses similar game mechanics, and while they are light and simple, it clearly had an added benefit for users. Some users also mentioned gamification as a loyalty draw for them. In the example below, P11, a new user, discusses his first gamification experience through mobile payment:

I think it is cool to be able to use my phone to [participate in gamification]... I am probably more inclined to go to the deli that accepts LevelUp than other delis in my neighborhood... more for the gamification... - P11, new user

Two existing users also mentioned that gamification had a significant role in their positive user experience of mobile payment service. This was even after a year of usage. Specifically, P4 and P10 said that collecting and using loyalty programs made the shopping experience more interesting than using cash or a credit card for payment.

\section{Social Perception}

Participants generally felt positive about the social perception of using mobile payments. First, they talked about the positive aspects of being watched by other people when they were using a mobile payment service in a store. Participants often described how they felt "cool" using mobile payments because it was a new technology and not everybody was using it.

Second, they felt that mobile payments allowed them to make payments faster (than debit or credit) which helped the lineup move faster. They felt that this, in turn, eased any social tensions created by impatient employees or customers. This is despite whether others were actually impatient or not. 
[Other store patrons] like it because the line moves faster you can see they are impatient if you are looking for cash or a lot of extra steps for [the employee] to key in a credit card purchase. - P21, existing user

Third, participants described that they were sometimes even engaged in a positive discussion around mobile payments with friends or customers during or after purchases. Existing users also described how many of their friends used mobile payment services and they felt they were becoming popular because it was a "topic of discussion" within their work or school environments. In order for them to appear like they were part of their community, they felt they should be able to comment on the new technology.

There was this discussion in the community I am in. It definitely prompted [my mobile payment usage] in that sense... I know a lot of techies... the community would be, I guess, the geek or techie community. - P3, existing user

\section{Regulatory Avoidance}

A number of participants also mentioned that they used a form of mobile payment service to get around regulatory restrictions from banks. Some examples included credit limitations, much like pre-paid visas (e.g., PayPal); ordering gaming licenses from countries that did not accept the user's local credit card information; making payments from consumer to consumer or small businesses; and, charities collecting payments without a POS terminal from a bank (e.g., Square). For example, P1, an existing user, told us he used Square for his business so he did not have to set up a merchant account at a bank. Being able to accept credit cards as a small business altered the way he sells merchandise. He described how mobile payment services have allowed him to accept credit cards and thus expand his business.

It is well known that the poor trust relations and fear between banks and patrons have helped drive the success of mobile payment services in developing countries [7]. While North American bank systems do not have the same level of mistrust, our participants still used mobile payment services to avoid bank charges and regulations; however, the reported types of charges and regulations were specific to North America.

\section{USER CHALLENGES WITH MOBILE PAYMENTS}

Naturally, like any new technology, users also experienced challenges with mobile payment services. In this section, we present the challenges that users faced, which focused on a lack of payment options around their routines, usability issues, pre-purchase anxiety, and trust issues.

\section{New Users' Routines and a Lack of Benefits}

For new users, the value of routines for using mobile payments was still high. Yet not all had a purchasing routine that mapped well to using a mobile payment service. For this reason, four new users did not enjoy the service, while an additional three new users did not make purchases. For example, P19 explains how mobile payments did not fit his purchasing routines:
The Starbucks one is nice, it sounds quite cool but I don't use-- I don't buy Starbucks often enough to use it. - P19, new user

This quote speaks to the fact that mobile payments are currently only available in a small number of instances and stores within North America. As an example, it also illustrates that people who use Starbucks can easily use mobile payments because Starbucks has a payment app. Yet people who drink coffee at another location that does not support mobile payments will not have the same opportunities to use the payment method. This suggests that, over time, if more stores adopt mobile payment services as a payment option, the practices of new users might be different. Until this point, new users may not see the point of using a store "once in a while" simply so they can use a mobile payment option; indeed, this is what our participants told us.

Many new users also told us that they did not see the benefits in using mobile payments instead of a credit card, despite understanding how to use mobile payment options. That is, the mobile payment service seemed to offer the same benefits as a credit card to them, e.g., payment without cash. Yet they were already able to do this with a debit or credit card. Some participants told us in their final interview that they felt they would not use mobile payment services in the near future unless their routines changed.

I think [I would maybe use mobile payments in the future] because it could become more popular and we are moving towards that, maybe when my friends and family start using it and when it becomes a norm. - P19, new user

This illustrates that people are often fairly engrained within their current payment methods. It suggests that unless there is a larger societal shift in payment options and usage that some people simply will not change their practices.

\section{Mental Model Development \& Usability Issues}

Mental models often help shape behavior and explain a person's thought process on how something works [4]. Some participants within the new user group, described how they just could not understand how paying with their phone worked or how to start the process. For example, P16, a new user, explained during the interview that she had a complete lack of knowledge around what direction to proceed to even start the study. She said she did not know what apps to look for or download. As a technically engaged individual this was shocking for her. She told us:

I didn't know, like when I agreed to do it, I didn't know what apps to download, I didn't even know what to look for. - P16, new user

Other users made specific comments around not having the "mental model" to see their smart phone as a payment source. P20, a new user, was surprised that payment over a phone was even possible. While P17, a new user told us "it never even occurred" to him to use his cell phone to make a purchase. For him the thought of doing something serious like making a payment on the same device he uses to make "stupid text messages" from seemed unheard of. In his 
mind, the mental model for what a cell phone does did not include paying for items.

Participants also complained about a lack of adequate feedback with mobile payment services. Many participants indicated they did not know how much they were being charged before or during the transaction. This was true for a number of payment methods (e.g., Starbucks app and Square). For example, P11, a new user, talks about the delay in being notified how much he spent at a local deli:

A few minutes later you get a message on your phone saying you just used LevelUp and the amount was $X$ so it's just for the split second when they punch in the number they put in and then they charge your phone [you don't know how much you are being charged]. - P11, new user

A common theme across mobile payment services was a lack of visual or audio indicators for feedback around transactional information. Users felt it was unclear when a transaction went through as there was little indication, leaving them unsure if the transaction was complete. In addition to lack of social cues from the employees, this lead to participants being concerned that they might have been charged twice.

\section{Pre-purchasing Anxiety}

A common trend for both user groups was pre-purchase anxiety, despite the previously reported positive social perceptions associated with mobile payments. Before participants made a purchase, they often tried to get their phones ready and were nervous that the phone would not be ready to be scanned when it was their turn in line. They harbored anxiety that the phone would turn to screen saver mode, and then require a password to be entered, or the barcode would not be ready to be scanned. Participants told us that this could cause a longer wait for people in lines, confusing discussions with store clerks, feelings of inadequacy in not being able to know how to use the technology, or the need to switch to another payment form. For example, P12's diary had numerous entries on prepurchase anxiety:

I like making sure I have the screen ready -- that my screen does not go to sleep. It has more to do with my performance anxieties than the app or the interaction. - P12, new user

Overall, the amount of tension around using mobile payments was far greater than participants thought they would feel. Surprisingly, while these feelings did diminish over time, they were still mentioned by existing users.

\section{Trust Concerns}

We found several trust concerns in relation to using mobile payments. These included concerns about around access to information and fragmented payment solutions.

\section{Access to Information}

First, four existing users reported having serious issues with information access across a variety of mobile payment systems. They were worried that other people may be able to access their payment information or other data on their smartphones.

For example, P10, an existing user, explained how one mobile payment service he used was tied to his email account. His email account was hacked, which he assumed compromised his financial data. As a result, P10 no longer used that particular service, but still uses other mobile payment services.

P6, also an existing user, described a situation she had when using a pay-by-phone parking service for metered parking. She explained how the system was tied to her phone number when you call in to pay and that she had just recently had her phone number changed. The system did not allow her to change her profile, which resulted in her having access to someone else's account. This, in turn, left her with the assumption that someone had access to her account too. She told us the situation was "worrisome."

Another existing user reported having trust concerns over the security of paying through a barcode displayed on his phone. Because of this, he and his sister did a test where he sent his sister a screenshot of the barcode and she displayed the picture of the barcode at the store to make a purchase. To both their surprise, the barcode scanned successfully at the store and his sister was able to purchase.

Both user groups had trust concerns around security of personal information that they entered over Wi-Fi or other networks. For example, P20 had extreme concerns around the contract he had to sign to use the Starbucks app, as well as little understanding towards how the process would work. He even was concerned that he might be giving the company access to all of the data on his phone.

Issues around access to information also occurred for the viewing of information in person. Some users had concerns about data on their screen being visible to outsiders. For example, P8, an existing user, told us, "It has to do with money, it's kind of private, so then I try not to show anyone." P16, a new user, told us that she was nervous entering her credit card information on a bus.

I found [a payment app] which I could add [money] to with a credit card... so I added $\$ 20$ and paid with my card. I did it on the bus and I think that made me a little nervous, like, can anybody see me taking my card out? - P16, new user

\section{Fragmented Payment Solutions}

Second, some participants told us that they did not like to leave money or personal information untouched and not regularly used. As a result, they really disliked the idea of creating multiple mobile payment service accounts for each vendor that they might use. Instead, they wanted just a single global account so they would not accidentally mishandle their money by, perhaps, forgetting about it in an account. They were also concerned that they may not be able to keep track of account charges across multiple account in cases of potential fraud. Participants specifically told us they needed to "touch" their money often (e.g., by 
spending small amounts with each mobile payment service) to ease trust concerns and overall fear of money loss.

For example, P17, a new user, mentioned how he had information saved in a PayPal account from years ago. He expressed concern about not regularly using the account and felt uneasy about having his information just "languishing" there for years. This ultimately gave him a negative feeling towards PayPal. He mistrusted PayPal as a brand and the information that was stored with them.

Similarly, P19, a new user, also said he would not use a system for payment unless it was accepted at nearly all of the stores he frequented. He, too, disliked the idea of having money in numerous places and was concerned this would lead to a loss of money as it "just sits in an account somewhere."

\section{DISCUSSION}

Our findings showed a range of user practices with mobile payment services along with clear successes and challenges in using mobile payments. We discuss the implications of these findings and further reflect back on our related work section, as well as introduce new literature as a lens to interpret key components of our findings.

\section{Mental Model Development and Designing for Routines}

First, our results illustrated clear trends around why existing users continue to use mobile payment services long term. In our study, all existing users perceived their mobile payment use as easier and faster than other payment methods. They also described how their smartphone was often a more convenient solution to make payments than money or credit/debit cards. Yet in contrast, our study also revealed why some users may not adopt mobile payment services, or why they may chose to not use them even initially. Here we found that some new users were almost puzzled by why people might find mobile payment services to be easier and faster than the current payment methods they used. Our results also found that some users lacked the mental model of how mobile payments would work. This was a key factor that affected the usefulness of mobile payments.

As mentioned, Hinman and Matovu [7] found similar mental model and conceptual gaps between their users and mobile payment use. While our participants understood the exchange of funds for services, some did not seem to conceptually understand payment through their smartphones and the benefits associated with it. Considering that Hinman and Matovu's study was conducted in 2002-over ten years ago-this result is especially surprising. One would expect that the idea of paying for items using a phone would be more commonly understood than what we saw. Certainly as mobile payment services become more readily available in North America, it is likely that the issues around mental model will slowly disappear as users get used to the idea that smartphones can support payments.
Yet we also feel there are design directions that could help support the uptake of mobile payment services to help increase adoption and the usefulness of the technology. Participants in our study very clearly found mobile payments most valuable when they focused on routine and habitual activities. In fact, both new and existing users expressed this sentiment. We had expected that would be the case for existing users but not new users. This suggests clear benefits for mobile payment services that target habitual or routine activities as a starting point for designs. For example, these may include mobile payment options for gas, groceries, and other routine purchases. Over time, as users develop practices around habitual purchases, they would develop a mental model of how mobile payments work, which could then extend to understanding how mobile payment services could be more broadly used for other non-routine purchases. This extends past work by Mallat [16] who suggested mobile payments are most compatible with small value payments. We now see additional compatibility with routine purchases.

\section{Gamification and Entertainment}

Our study also revealed that one of the key benefits for new users of mobile payments over other payment methods was the gamification and reward features. These attributes created a more emotional and exciting experience. Given this, we believe that gamification elements coupled with a mobile payment service that is perceived to be useful will entice new users to adopt mobile payment services. Thus, gamification can act as a complementary component for mobile payment designs.

Yet the question is whether or not such features would continue to attract users longer term. Lindqvist et al. [13] investigated Foursquare users and found that the gamification element of collecting badges was a decreasing motivator for usage over time; users had a slow decline of participation after 200-300 days. In our case, we only had two veteran users comment that gamification in mobile payment services still had long term appeal after a year. This suggests further study of the long-term effects of gamification on mobile payments.

\section{Social Cohesion}

Part of the positive experiences we found for mobile payment related to social cohesion. Ling [14] describes social cohesion as a strong 'current' in society and strong bonds linking individuals, which affects how we interact with one another and what we know about each other. This is the opposite of individualism [14]. Related to social cohesion is the idea that people have negative attitudes towards people using mobile phones in public situations and locations $[12,14]$. That is, using one's mobile phone in public areas has been deemed socially rude and is often met with negative connotation [12,14]. However, in our findings, participants described the opposite. They felt that the use of mobile payments created a positive experience for people around them. They explained that this was 
because they were using their mobile phone in socially positive ways, which in this case was speeding up a store line and eliminating wait times for others. Participants felt their mobile payment activity allowed them to "help out" fellow patrons resulting in social cohesion [14]. Of course, there is the chance that while the purchaser thought the experience was positive for others, it may have in fact been unpleasant or annoying. We did not ask others present during mobile payment purchases about what they thought of the activity to know for sure. This suggests future work that investigates public reactions to mobile payment usage.

Of course, negative experiences around social cohesion can also obviously arise. As discussed in the findings, users 'fiddle' with their phones before use because of prepurchase anxiety, and this could negatively impact social cohesion if patrons are in groups (face-to-face) when purchasing. This also suggests design opportunities to make mobile payments less distracting for the payee. For example, in recent versions of Apple's iOS software, the phone's camera functionality is available from a locked screen with a single finger swipe. Payment options could similarly be integrated in such a manner if people feel safe with such easy access to payment options.

Mobile payments were also associated with a "coolness" factor when one was using them. Yet once mass adoption occurs, this coolness could easily diminish and it is not clear what feelings people may have toward the appearance of using the technology once this occurs.

\section{Trust Concerns}

Our findings also reported significant trust concerns amongst both types of users - new and existing. This differs heavily from work done in past mCommerce studies that have focused on purchasing products over the web [8]. Past work found that mechanisms to mitigate trust issues with mCommerce were prevalent and came in three distinct forms: family and friend recommendations, brand awareness, and leveraging trusted marketplaces such as iTunes and Google Play [8]. As a result, people did not have trust issues with their mCommerce shopping activities. In contrast, participants in our study did not find ways to mitigate their trust concerns. Instead, they simply had to "put up" with the issues, not purchase at all, or use another payment option. This is interesting because a large portion of transactions were done using apps from the same marketplaces reported by Hillman et al. [8]. Thus, brand awareness and trusted marketplaces were not enough to mitigate many users' trust concerns unlike other mCommerce shopping activities. Similarly, trust created by actually being physically present in a store was also not always present.

What is somewhat surprising is that the same trust issues observed by Mallat [16] over ten years ago were also described by participants in our study. Users were still concerned about network security, vagueness of transaction, and lack of control. Not only were users concerned that their mobile phone would get lost, stolen or hacked, we were presented with stories of this actually occurring. With these findings, addressing security and trust concerns seems essential to mobile payment success in the future.

Of course, trust concerns could simply go away over time, much like the mental model issues that some people have for mobile payments. Here continued and widening usage of mobile payments could see the easing of trust concerns. Yet there are also possible design avenues that could help speed up the easing of such concerns. First, many people had trust issues that revolved around data transmission. This suggests solutions that further enhance secure data transmission, or mobile payment designs that let users know that data transmission is in fact secure, if it is.

Second, we also recognize that currently mobile payment systems do not offer the same institutional backing as one might find with a credit card company. For example, if fraudulent charges occur on a credit card, most credit card companies are quick to reverse such charges. In the case of mobile payment systems, such services may not exist or users do not know about them. This suggests new models for companies to provide institutional backing against fraud, or designs that highlight such backing, if it exists.

Third, participants also reported issues around strangers seeing one's smartphone screen and private data while transactions were being made. This suggests designs that obscure such information so it is viewable only by the user.

Lastly, participants were concerned about the fragmented nature of mobile payment solutions where one's money may reside in several places (e.g., PayPal, the Starbucks's App). This meant users could easily forget about their balance. This suggests mobile payment designs focused around a centralized hub that manages all transactions and balances. Of course, this type of solution would require partnerships between companies, which may not be possible. Alternative solutions could look at providing better feedback to users of balances (especially if they are untouched for a long time), or the ability to easily move money out of a mobile payment service if it is no longer being used.

\section{Limitations and Generalizability}

Our study comes with several limitations that suggest future research in this space. First, we note that our analysis focused on all types of mobile payment services instead of just one particular type. Studying a single service could have revealed more detailed findings about that particular service. Yet, despite this diversity in our study, we did not see variations in responses based on any of the mobile payment types that participants used. That said, because our study was a qualitative study and not a quantitative controlled study, we did not control for such variables nor did we look for cause and effect. Therefore, we suggest additional studies focused on specific types of mobile payments independently. 
Second, we studied North Americans as a group and only from major metropolitan cities. We did not see a difference in results from Canadians versus Americans; however, further investigation could be conducted to compare the two with a larger sample, especially if the countries end up developing unique e-wallet solutions.

Third, we caution that our study did not investigate the long-term adoption of mobile payments as might be found in a study that lasts several months to years. Instead, we focused on the first reactions of new users to mobile payment services along with the experiences of existing users who have already adopted the technology. This suggests an additional longitudinal study to complement our research.

\section{CONCLUSION}

To summarize, mobile payment services are in their infancy in North America. The potential to enhance users experience with faster and more useful transactions is possible. There is also potential for mobile payments to aid in social cohesion [14], which has previously been missing in mobile use. However, user challenges with mobile payments still exist. These include a perceived lack of need for the technology, and issues around mental model development and trust concerns. In order to move past these obstacles, this paper has outlined key areas for improved user experience: designing around users' routines and behaviors, trust mechanism development, and supporting gamification and social cohesion.

\section{REFERENCES}

1. Chemonics. Mobile Phone Banking Expands into Rural Philippines, retrieved from:

http://www.chemonics.com/OurStory/OurNews/Pages/ Mobile-phone-Banking-Expands-into-RuralPhilippines.aspx

2. Cho, D., Kwon, H., and Lee, H., Analysis of Trust in Internet and Mobile Commerce Adoption, 40th Annual Hawaii International Conference on System Sciences, pp. 1-10. (2007).

3. Davis, F. D., Perceived Usefulness, Perceived Ease of Use, and User Acceptance in Information Technology, MIS Quarterly, 13 (3), pp. 319-340. (1989).

4. Forrester, J., Counterintuitive Behavior of Social Systems, Theory and Decision, Volume 2, Issue 2, Springer, pp. 109 - 140. (1970).

5. Head, M. and Hassanein, "Trust in e-Commerce: Evaluating the Impact of Third-Party Seals", Quarterly Journal of Electronic Commerce, 3(3), (2002), pp. 307325.

6. Henkel, J., Handygestützte bezahlverfahren [Mobile payment]. In G. Silberer, J. Wohlfahrt, \& T. Wilhelm (Eds.), Mobile commerce (pp. 327-351). Wiesbaden, Germany: Gabler. (2002).

7. Hinman, R., and Matovu, J., Opportunities and Challenges for Mobile-based Financial Services in Rural
Uganda, Extended Proceedings of Computer-Human Interaction. pp. 3925-3930. (2010)

8. Hillman, S., Neustaedter, C., Bowes, J., and Antle, A., Soft Trust and mCommerce Shopping Behaviors, MobileHCI 2012. pp. 113 - 122.

9. Hillman, S., Neustaedter, C., Pang, C., and Oduor, E., "Shared Joy is Double Joy": The Social Practices of User Networks within Group Shopping Sites, CHI2013. pp. $113-122$.

10. Kalakota, R. and Robinson M., M-Business: The Race to Mobility. Mcgraw-Hill Trade, pp.1-84. (2001).

11.Kim, C., Mirusmonov, M., and Lee, I., An Empirical Examination of Factors influencing the intention to use Mobile Payment, Computer in Human Behavior Journal, pp. 310-322, (2010).

12. Kindberg, T., Sellen, Abigail, S., and Erik Geelhoed, Security and Trust in Mobile Interactions: A Study of Users' Perceptions and Reasoning. UbiComp 2004: Ubiquitous Computing. pp. 1-16. (2004).

13. Lindqvist J, Cranshaw J, Wiese J, Hong J, Zimmerman J., I'm the Mayor of my house: examining why people use foursquare - a social-driven location sharing application. In: Proceedings of CHI. ACM Press, New York, pp. 2409-2418. (2011).

14. Ling, R., New Tech, New Ties: How Mobile Communication is Reshaping Social Cohesion, Massachusetts Institute of Technology, (2008).

15. Luo, X., Trust Production and Privacy Concerns on the Internet - A Framework Based on Relationship Marketing \& Social Exchange Theory, IMM, 31,(2002).

16. Mallat, N., Exploring Consumer Adoption of Mobile Payment - A Qualitative Study, Journal of Strategic Information Systems 16, pp. 413-432, (2007).

17. Ondrus, J., and Pigneur, Y., Towards a Holistic Analysis of Mobile Payments: a Multiple Perspective Approach, Electronic Commerce Research and Applications 5 (3), pp. 246-257, (2006).

18. Ong, J., Alipay Dominates as Online Payment in China Top \$150 Billion in Q3: Report, Retrieved from: http://thenextweb.com/asia/2012/12/03/alipay-leadsonline-payments-in-china-after-nearly-rmb-1-trillion-intransactions-in-q3-2012/

19. Twomey, M., Cashless Africa: Kenya’s Smash Success with Mobile Money, Retrieved from http://www.cnbc.com/id/101180469, (2013).

20. Ventakesh, V. Ramesh, V., and Massey, A. P. Understanding usability in mobile commerce. Communications of the ACM, Vol. 46(12), pp. 53-56. (2003). Model, Information and Management 42 (5), pp. 719-729, (2005).

21.Zmijewska, A., and Lawrence, E., Implementation Models in Mobile Payment, In Proceedings of the IASTED International Conference, Puerto Vallarta, (2006), pp.19-25. 